\title{
A Study on the Effects of Children's Attitude toward Elder by Intergenerational Programs
}

\author{
Meng-Chieh Chao
}

\begin{abstract}
This study explored the effect on the changes of children's attitude toward elder, after both had participated in the intergenerational program, by quasi-experimental design with the pretest and the posttest. The intergenerational program took 8 weeks. The participants were 54 children from kindergarten and eight elderly people in Taipei. The study of children's attitude toward the old people shows the findings as follows: a) The fact that children live with grandparents have effect on the affection of children toward the elders. b) Intergenerational program increased the children's social and physical cognition in older people. In addition, elderly people were interviewed shortly after they completed the intergenerational program. Following facts were obtained from the interview: Elderly people had also improved their life meaning after they took part in intergenerational learning activities.
\end{abstract} $\begin{array}{ccc}\text { Index } & \text { Terms-Intergenerational } & \text { program, } \\ \text { intergenerational learning, children's attitude toward elder. }\end{array}$

\section{INTRODUCTION}

In Taiwan, the aged population increases steadily as time passes by. In 2018, the aged population, 65 -and-older seniors, constituted $14.05 \%$ of total population. Since then, Taiwan has stepped into an aging society. Elderly people's wisdom and experiences are valuable. The younger generations can benefit from the elderly people's wisdom and experiences. In 1995, C. D. Ekstrom and X. Pei pointed out the elderly people's learning and participation method in recent years serves as a paradigm in which elderly people have turned from social dependents into resource providers, from social isolators into intergenerational connectors, and from ability-disadvantaged people into lifetime experience providers [1]. For this reason, the learning model which stresses sharing and assistance among different generations intergenerational programs - are meaningful for elderly people and the children. Intergenerational programs is a meaningful and continuous program designed for resource-exchange and mutual learning between elderly people and younger generations, and with the intergenerational program [2], elderly people act as guilders for the younger generations in order to eliminate the stereotype between different generations and thereby encourages all generations to respect the difference among them. The younger generations can benefit from them. An

Manuscript received January 30, 2019; revised September 23, 2019.

Meng-Chieh Chao is with the Department of Early Childhood Educare, The Ching Kuo Institute of Management and Health, Taiwan (e-mail: shchao@ems.cku.edu.tw). intergenerational program for younger generations and elderly generation were to exchange resources and learn from each other on a continual and purposeful basis [3]. Intergenerational learning or intergenerational program issues are crucial in elder education and are relevant to early childhood education. Here is no doubt that intergenerational programs are a perfect learning method for elderly people to make best use of their skills and at the same time learn something new to them. Moreover, intergenerational programs allow elderly people to renew the meaning and purpose of life when they participate in the activities and interact with others, which are very important for their aging process. According to the study of elderly people, however, intergenerational programs have imposed positive influence on elderly people and improved the factors related to elderly people's meaning in life such as well-being and satisfaction with life. Elderly people who took part in the intergenerational programs held by preschools for 3-4 years old children. Eight weeks after elderly people were paired with children, elderly people exhibited significant difference in two aspects: 1) The social distance between elderly people and children decreased, and 2) Elderly people improved their self-esteem, control and satisfaction with life [4]. Early research indicates, that elderly people improved their social awareness after they took part in the intergenerational programs held in nursing homes [5].There was another similar study which divided 15 elderly people into control group and experimental group. The elderly people of experimental group joined an intergenerational program in a preschool where they were paired with children. The research results confirmed the correlation among elderly people's mobility, perceived control and self-esteem [6]. By taking part in intergenerational programs, elderly people have identified the positive meaning in their life which guides them to face their life and to improve the value of their life.

From this study, we gain the information that young children have a stereotype of the elders, mostly negative, and focus on the decline of the elder's physiology [7]. In addition to affecting the individual's attitude towards the elders, age discrimination directly affect the development of self-concept and the ability of individuals to accept aging [8]. In the intergenerational program, elderly people act as guilders for the younger generations in order to eliminate the stereotype between different generations and thereby encourages all generations to respect the difference among them .In addition, changing attitudes towards the elders should start from early childhood.

In a survey of intergenerational learning, there is no 
consistent conclusion on the attitude of young children to the elders. Due to the reasons of different intergenerational programs, research tools for measuring attitudes, and the experience with their grandparents [9], little attention has been paid in the context of the intergenerational program, such as the contact conditions, and the role of the elders in the intergenerational interaction. This research is to explorer whether the quality or quantity in the intergenerational learning is more influential to the children's attitude toward elders, meanwhile also aimed at understanding the children who attitudes toward elders who live together, and how the intergenerational experience help positively change children's attitudes toward aging. Based on the discussions stated above, this study also aimed to find out elderly people's changes of individual value, sense of direction, sense of autonomy and sense of fulfillment after they took part in intergenerational programs.

\section{RESEARCH DESIGN}

\section{A. Subjects}

A convenience sample consisting 54 children aged 6 years old was obtained from two classes in the same kindergarten in Taipei. One class was the experimental group and the other was the control group .Half of the 54 children live with their grandparents. Researcher invited eight elderly people to participate in the intergenerational program.

\section{B. Materials}

To measure how children perceived elderly people, the questionnaire were divided into two parts, the semantic one and picture series one, were revised from The Children's Attitude Toward Elderly Questionnaire by Jantz et al. [10]. Considering the cognitive ability of young children, the semantic questionnaire provided the opposite characters in 4 points scale to assesses the social cognition, physical and mental cognition of children's attitudes toward elderly people .The picture series questionnaire, ask children to choose a visual pictures of a men at ages twenty, forty, sixty and eighty, and measure the age concept, affection and behavioral of elders. The instrument were tested by expert validity and the Cronbach $\alpha$ score ranging from .73 to. 80 .

\section{Procedure}

This study chose a kindergarten in Taipei as the experiment site in which activities were arranged once a week, one hour each time, eight weeks in total. Researcher invited eight elderly people - six females and two males, age between 62 and 78, graduates of junior college or higher education institution to participate in the intergenerational program. , and the intergenerational program were designed by them who are interested in or have expertise such as Tai Chi, native history stories, cat's cradle tricks et al .The elders to be the main teacher took turns per week. After giving lectures, elderly people remained in the classroom to chat and interact with children.

Before the intergenerational learning program, each child met with the researcher individually and completed the questionnaire. After 8 weeks, all the children use the questionnaire again to exam the difference. In an effort to find out the influence on elderly people imposed by the intergenerational program. Besides, in an effort to find out the influence on elderly people imposed by the intergenerational program, researcher discussed the meaning in life with the elderly people two weeks after the intergenerational program was completed.

\section{RESULT AND DisCUSSION}

\section{A. Analysis of the Difference in Children Who Living with Grandparents or Not, Whose Attitude towards the Elderly}

Attitudes evolve and develop based on cultural and familial value systems. They are reinforced by experiences, information and other outside influences. Early research indicates that a lack of intergenerational contact was identified as a reason for children developing negative attitudes [11]. Furthermore, there are significant difference between the children who lived with grandparents or not in this research. Table I shows the pre-test of the attitudes of the elderly with the grandparents in the study on the affection category was significantly higher than that of the children who did not live with the grandparents. $(t=3.08 ; p<0.01)$, which means, that with an increase in contact with the elders, children exhibit more positive affective attitudes toward elders.

TABLE I: THE SCORE OF THE DIFFERENCE BETWEEN CHILDREN WHO LIVED WITH GRANDPARENTS OR NOT ON THE PICTURE SERIES QUESTIONNAIRE

\begin{tabular}{lllllc}
\hline category & $\begin{array}{l}\text { live } \\
\text { together }\end{array}$ & $N$ & $\overline{\mathrm{X}}$ & $S D$ & $t$ \\
& Or not & & & & \\
\hline sum & together & 27 & 2.24 & 0.41 & 1.19 \\
& not & 27 & 2.06 & 0.65 & \\
\hline Age concept & together & 27 & 2.38 & 0.78 & -1.56 \\
& not & 27 & 2.81 & 0.76 & \\
\hline $\begin{array}{l}\text { Affection of } \\
\text { elder }\end{array}$ & together & 27 & 2.39 & 0.84 & $3.08^{* *}$ \\
& not & 27 & 1.67 & 0.89 & 1.64 \\
\hline $\begin{array}{l}\text { Behavior of } \\
\text { elder }\end{array}$ & together & 27 & 1.87 & 0.77 & \\
& not & 27 & 1.48 & 0.97 & \\
\hline
\end{tabular}

* ${ }^{*} p<.01$

\section{B. Homogeneity of Groups before Treatment}

This study was conducted on two groups, the experimental and control groups. In order to have homogeneity in each group, pre-test should be considered. Table II shows that after an independent sample t-test had been conducted, there was no significant difference found among pretest scores of the control and experimental groups in Semantics test $(t=$ $1.02 ; p>0.05)$.

In addition, children's views of aging questionnaire score of experimental group children before treatment $(=2.14)$ was lower than control group children' score $(=2.16)$, but this difference is not significant to the $95 \%$ confidence interval. These two groups appear the equal attitude toward the elders 
before the intergenerational learning.

TABLE II: THE SCORE OF EXPERIMENTAL GROUP AND CONTROL GROUP PRE-TEST ON THE SEMANTIC QUESTIONNAIRE

\begin{tabular}{llcccc}
\multicolumn{5}{c}{ PRE-TEST ON THE SEMANTIC QUESTIONNAIRE } \\
\hline category & group & $N$ & $\overline{\mathrm{X}}$ & $S D$ & $t$ \\
\hline sum & EG & 28 & 3.00 & 0.36 & 1.02 \\
& CG & 26 & 2.86 & 0.55 & \\
\hline $\begin{array}{l}\text { Social } \\
\text { cognition }\end{array}$ & EG & 28 & 3.00 & 0.54 & 1.84 \\
\hline $\begin{array}{l}\text { Physical } \\
\text { and mental } \\
\text { cognition }\end{array}$ & EG & 28 & 2.71 & 0.63 & \\
\hline
\end{tabular}

TABLE III: THE SCORE OF EXPERIMENTAL GROUP AND CONTROL GROUP

\begin{tabular}{lccccc}
\multicolumn{5}{c}{ PRE-TEST ON THE CHILDREN's VIEWS OF AGING } \\
\hline category & group & $N$ & $\overline{\mathrm{X}}$ & $S D$ & $t$ \\
& & & & & \\
\hline sum & EG & 28 & 2.14 & 0.53 & -0.11 \\
& $\mathrm{CG}$ & 26 & 2.16 & 0.57 & \\
& & & & & \\
\hline Age concept & EG & 28 & 2.46 & 0.83 & -0.826 \\
& $\mathrm{CG}$ & 26 & 2.64 & 0.74 & \\
& & & & & \\
\hline $\begin{array}{l}\text { Affection of } \\
\text { elder }\end{array}$ & EG & 28 & 2.21 & 0.96 & 1.55 \\
& $\mathrm{CG}$ & 26 & 1.83 & 0.87 & \\
\hline $\begin{array}{l}\text { Behavior of } \\
\text { elder }\end{array}$ & EG & 28 & 1.59 & 0.86 & -0.74 \\
& $\mathrm{CG}$ & 26 & 1.77 & 0.92 & \\
\hline
\end{tabular}

\section{After Intergenerational Learning, Children's Attitude toward Elders}

The pre- test score suggested no significant differences between the two groups of children, while the post - test clearly indicated a positive change. Table IV shows the children of experimental group attitude toward elders. T-test result indicate that there were significant difference in the data regarding the social $(t=-3.01, p<.01)$, physical and mental category $(t=-6.06, p<.001)$ in Table III.

TABLE IV: THE SCORE OF EXPERIMENTAL GROUP PRE-TEST AND POST-TEST

\begin{tabular}{lcccc}
\multicolumn{5}{c}{ ON THE SEMANTIC QUESTIONNAIRE } \\
\hline category & $n$ & $\overline{\mathrm{X}}$ & $S D$ & $t$ \\
& & & \\
\hline & Pre-test & Pro-test & Pre-test & Pro-test
\end{tabular}

\begin{tabular}{lcccccc}
\hline sum & 28 & 3.00 & 3.40 & 0.36 & 0.41 & $-5.67 * * *$ \\
\hline $\begin{array}{l}\text { Social } \\
\text { cognition }\end{array}$ & 28 & 3.00 & 3.31 & 0.54 & 0.54 & $-3.01^{* *}$ \\
\hline Physical & 28 & 2.99 & 3.45 & 0.38 & 0.43 & $-6.06 * *$
\end{tabular}

Physical

and mental

cognition

$* * p<.01 * * * p<.001$

In addition, children also presented the positive attitude change toward elders in Table V. There were significant difference in the post-test. The score of children's age concept $(t=-3.22, p<.01)$, behavior of elder $((t=-2.12, p$ $<.05)$. This result shows that the intergenerational learning implemented on the experimental group dramatically enhanced children's attitudes toward elderly.

One exception is presented in the affection of elder category, the post-test score $(=2.29)$ was higher than the pre-test $(=2.21)$. There is no significant difference among pre-test and post-test scores of affection of elders. One of the reasons for these result is that changing the affection of elders should take a long time to get along with each other and to establish stability relationship.

TABLE V: THE SCORE OF EXPERIMENTAL GROUP PRE- AND POST-TEST ON THE CHILDREN'S VIEWS OF AGING

\begin{tabular}{lcccccc}
\multicolumn{7}{c}{ THE CHILDREN'S VIEWS OF AGING } \\
\hline category & $n$ & \multicolumn{2}{c}{$\overline{\mathrm{X}}$} & $S D$ & & $t$ \\
& & Pre-test & Pro-test & Pre-test & Pro-test & \\
\hline sum & 28 & 2.14 & 2.47 & 0.53 & 0.41 & $-3.23^{* *}$ \\
\hline Age concept & 28 & 2.46 & 3.00 & 0.83 & 0.54 & $-3.22^{* *}$ \\
\hline $\begin{array}{l}\text { Affection of } \\
\text { elder }\end{array}$ & 28 & 2.21 & 2.29 & 0.96 & 1.04 & -0.43 \\
\hline $\begin{array}{l}\text { Behavior of } \\
\text { elder }\end{array}$ & 28 & 1.59 & 1.88 & 0.86 & 0.69 & $-2.12^{*}$ \\
\hline$* p<.05 * * p<.01$ & & & &
\end{tabular}

\section{Control Group Children's Pre-and Post-test Score}

Table VI and VII show that there are no significant difference among pre and post-test scores of children's attitude toward elders in the control group $(t=-0.49, t=-1.55$, $p>.05)$. This result reveals that lack of intergenerational learning in the control group did not enhance children's attitude toward elders.

TABLE VI: THE SCORE OF CONTROL GROUP PRE- AND POST-TEST ON THE SEMANTIC QUESTIONNAIRE

\begin{tabular}{|c|c|c|c|c|c|c|}
\hline \multirow{3}{*}{ category } & \multicolumn{5}{|c|}{ SEMANTIC QUESTIONNAIRE } & \multirow{3}{*}{$t$} \\
\hline & $n$ & & $\overline{\mathrm{X}}$ & $S D$ & & \\
\hline & & Pre-test & Pro-test & Pre-test & Pro-test & \\
\hline sum & 26 & 2.86 & 2.82 & 0.55 & 0.49 & -0.49 \\
\hline $\begin{array}{l}\text { Social } \\
\text { cognition }\end{array}$ & 26 & 2.70 & 2.69 & 0.62 & 0.57 & -0.17 \\
\hline $\begin{array}{l}\text { Physical } \\
\text { and mental } \\
\text { cognition }\end{array}$ & 26 & 2.96 & 2.91 & 0.59 & 0.50 & -0.26 \\
\hline
\end{tabular}

TABLE VII: THE SCORE OF CONTROL GROUP PRE- AND POST-TEST ON THE CHILDREN'S VIEWS OF AGING

\begin{tabular}{lcccccc}
\hline \multicolumn{7}{c}{ CHILDREN'S VIEWS OF AGING } \\
\hline category & $n$ & $\overline{\mathrm{X}}$ & & \multicolumn{2}{c}{$S D$} & $t$ \\
\hline sum & 26 & 2.16 & 2.36 & 0.57 & 0.50 & -1.55 \\
\hline Age concept & 26 & 2.64 & 2.93 & 0.74 & 0.72 & -1.46 \\
\hline $\begin{array}{l}\text { Affection of } \\
\text { elder }\end{array}$ & 26 & 1.83 & 2.21 & 0.87 & 0.86 & -1.83 \\
\hline $\begin{array}{l}\text { Behavior of } \\
\text { elder }\end{array}$ & 26 & 1.77 & 1.67 & 0.92 & 0.93 & 0.58 \\
\hline
\end{tabular}

\section{E. Analysis of Post-test Difference between Experimental Group and Control Group}

After removed the score of pre-test, there were significant difference in the post-test between experimental and control group $(F=25.92, p<.01)$ in Table VIII.

TABLE VIII: THE ANALYSIS OF COVARIANCE (ANCOVA) SCORE OF POST-TEST ON THE SEMANTIC QUESTIONNAIRE

\begin{tabular}{lcccc}
\multicolumn{5}{c}{ POST-TEST ON THE SEMANTIC QUESTIONNAIRE } \\
$\begin{array}{l}\text { Source of } \\
\text { variation }\end{array}$ & $S S$ & $d f$ & $M S$ & $F$ \\
\hline Sum & & & & $25.92^{* * *}$ \\
$\begin{array}{l}\text { between-group } \\
\text { variance }\end{array}$ & 3.18 & 1 & 3.18 & \\
within-group & & & & \\
\hline
\end{tabular}




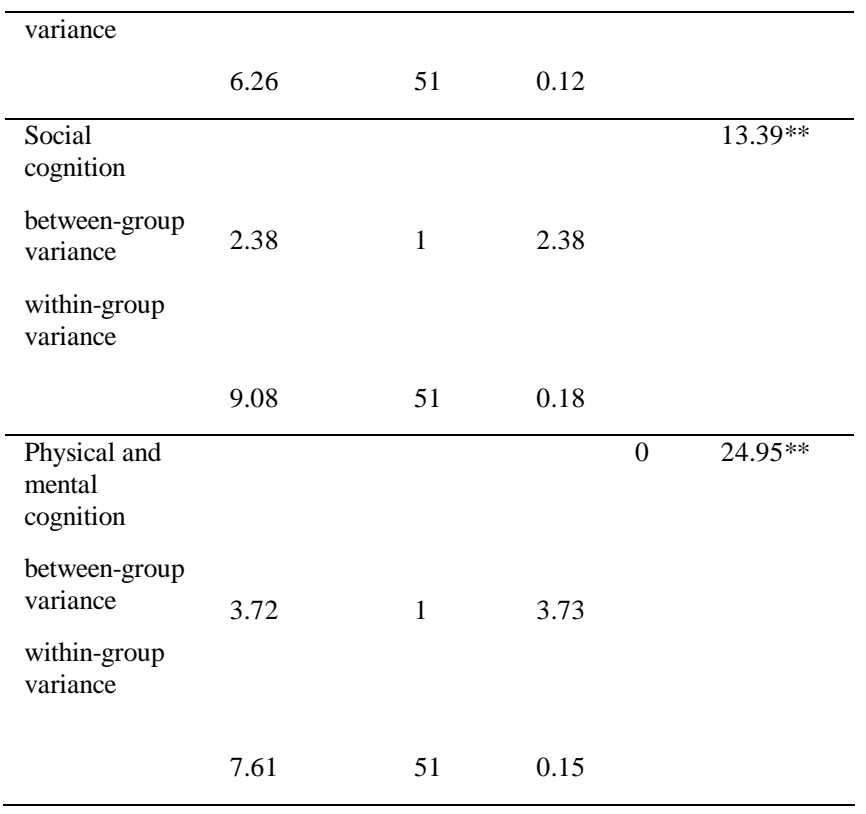

${ }^{*}{ }^{*} p<.01$

Upon completion of intergenerational program, the children of experimental group have changed their cognition of elderly people and established a positive attitude towards the elderly people. There are two possible reasons for the changes. Firstly, children spent time with elderly people. Children took part in the weekly activities and learned something from elderly people through the activities. Secondly, the activities were attractive to the children. As a result, children changed their impression of elderly people and built a positive cognition of them. Regarding children's cognition of elderly people's behaviors, children interacted with elderly people in the intergenerational program and observed how elderly people handled their daily affairs. Moreover, elderly people exhibited their knowledge and skills in the weekly activities. As a result, children understood that elderly people have the abilities to help others.

As to children's affection for the elderly people, the posttest has exhibited a higher mean than the pretest. Nevertheless, there are no significant difference among pre and post-test scores. The number of activities was probably not enough for the children to establish a steady and intimate relationship with the elderly people although they spent some time together.

Upon completion of intergenerational program, some children have dramatically changed their attitude towards elderly people. According to the author, there are several possible reasons for the changes: 1) Previous researchers focused on elementary school children. They exhibit a steady cognition and attitude toward elderly people. Young children, however, do not exhibit any steady attitude towards elderly people. As a result, no difference was found between pretest and posttest. 2) Young children need some time to adjust their affection and attitude towards elderly people. This study has found the significant difference between children's cognition of elderly people and elderly people's social cognition, but did not find any difference in all other aspects, probably because intergenerational program is designed to provide elderly people an opportunity to help children as opposed to the aging education. Intergenerational program does not necessarily provide a tangible goal each week. This is why intergenerational program is unable to help children construct the affection of elderly people right away. Children need more time to transform their intergenerational experience into emotions. The intergenerational program was too short to serve this purpose. 3) Intergenerational program has to provide more opportunities for children to interact with elderly people. This intergenerational program focused on lectures, hardly giving children an opportunity to assist the elderly people. As a result, children did not exhibit any difference in their attitude towards elderly people.

After analyzing the interview data for elderly people, The individual value sensed by elderly people after they took part in intergenerational program. They satisfied with their teaching performance. Each elderly person was responsible for one activity. In each and every weekly activity, the children took the initiative to greet the elderly people. This study found that the children's feedback has resulted in elderly people's positive attitude, which conformed to Mendis' research results. This study indicated the changes of two aspects exhibited by the elderly people who took part in intergenerational programs, namely, 1) The social distance between elderly people and children decreased, and 2) Elderly people improved their self-esteem, control and satisfaction with life. Elderly people have reached the "integrity vs despair stage" introduced by Erik H. Erikson. In the very last stage of their life, elderly people are faced with an urgent need to reflect on and integrate their memories. By taking part in intergenerational activities, elderly people can reflect on their life experience including their childhood memory, working experience and the affections with family members. Sense of direction refers to the goal of life and the future plan. After taking part in intergenerational program, elderly people said they felt a sense of direction, including the follows:

1) An enhanced focus of life

All elderly people had created a schedule for themselves after they retired. Then, they agreed to participate in the intergenerational program and adjusted their schedule for this program. They did their best to prepare their lectures, treating the lectures as an important task in their life.

2) Satisfying the need of helping others and learning

All elderly research objects said they had made up their mind to get their jobs done before they joined this program. By taking part in the intergenerational program, elderly people had an opportunity to materialize their dream. Most importantly, they were happy when they helped others. If elderly people continue to take part in the programs, they can regain the role that they have lost after retirement. According to the interviews, elderly people have improved the focus of their life after they took part in intergenerational program. By helping the children, elderly people have an opportunity to materialize their dream and return kindness to the society.

3) Sense of fulfillment

Sense of fulfillment refers to the feeling about the present life. Elderly research objects have improved their sense of 
fulfillment after they complete the intergenerational program. Details are described as follows:

1) Sharing experience with each other and learning from each other

The intergenerational program required elderly people to be present at the preschool weekly, eight weeks in total. Elderly people were required to interact with children in the classroom even though they were not lecturers. Thus, elderly people had the opportunity to watch each other's teachings and learn from each other. By doing so, each and every elderly person have learned something from each other.

2) Enriching life and having fun

For most elderly people, taking part in the intergenerational program once a week wasn't much work. For the elderly people who hardly take part in social occasions, however, intergenerational program was a great opportunity to have fun.

In general, elderly people have improved many aspects related to the meaning in life, such as individual value, sense of direction and sense of fulfillment. According to the data acquired from interviews, elderly people had become aware of their ability after they took part in intergenerational program. Moreover, this study has helped elderly people integrate their life experience and contribute their skills to the society. Meanwhile, elderly people have helped others and improved their life by taking part in the intergenerational program.

\section{CONCLUSIONS}

The result presented the children's attitude toward elders after intergeneration learning and tried to address two research question: 1) Have children who live with grandparents developed positive attitudes toward elders? 2) Can intergenerational experience help positively change children's attitudes toward aging?

Children who lived with grandparents in Taiwan, have significant differences in "children's affection for the elders" category, however there were no difference in others category. According to the research results acquired by this study, children's cognition of elderly people and behaviors remain unchanged if children live with grandparents. However, children's "affection for elderly people" are affected if children lives with grandparents and are taken care of by their grandparents. Children living with grandparents and seeing their grandparents daily are more likely to maintain positive emotions for elderly people than children not living with grandparents and not seeing their grandparents daily. It is therefore important to help children know elderly people better when we design intergenerational programs. Moreover, we have to help the children not living with grandparents or hardly spending time with grandparents to foster the emotions for elderly people in order to construct a positive relationship with elderly people.

According to these findings, educators should focus on the affective factors in the future intergenerational interaction. These include: increasing the frequency of interaction for children who are rarely with their grandparents, providing the intimate atmosphere in the intergenerational programs.

According to the pre-and post-test consequence, intergenerational learning can help positively change children's attitudes toward aging. Moreover, children's "cognition of elderly people's ages" and "cognition of elderly people's behaviors" have reached the significant level in pretest and posttest. Children could be elevated in to the social, physical and mental category, children's age concept, and the behavior of elders. In conclusion, intergenerational learning can provide an unbiased perception of older adult characteristics, and reduce the aging stereotype. Furthermore, educators design intergenerational learning that aim to reduce ageist attitude, it is have to appear the wisdom of older adults. The quality interaction that provide the children were helpful to decrease the aging discrimination, However, the affection between children and elders need more stable and continuous interaction to help children to change the attitudes.

After taking part in intergenerational program, elderly people found the meaning in their life has been enriched.

This study has found that, upon completion of intergenerational program, elderly people were satisfied with their performance as instructors and thus improved their sense of individual value. Elderly people were delighted with children's positive feedback, and at the same time integrated their past and cherished the present moment. The intergenerational program helped elderly people improve their focus of life, provided an opportunity for elderly people to help others and learn something at the same time, and thus enhanced their sense of direction. Moreover, the intergenerational program allowed elderly people to share experience with each other, learn from each other, enrich their life, and have fun.

After taking part in the intergenerational program, elderly people exhibited significant improvement in several aspects of their meaning in life, such as individual value, sense of direction and sense of fulfillment while less improvement of life meaning in their sense of autonomy.

This study found that, after elderly people completed the intergenerational program, they had exhibited significant improvement in several aspects of their meaning in life, such as individual value, sense of direction and sense of fulfillment while less improvement of life meaning in their sense of autonomy. According to social concepts, the sense of autonomy means the viewpoints about life and death, which have much to do with culture and religious belief. The elderly people taking part in the intergenerational program has enthusiastically participated in the related social affairs over the past years. This is why the short-term intergenerational program was unable to change their sense of autonomy, and therefore elderly people hardly exhibited any change about their sense of autonomy.

\section{CONFLICT OF INTEREST}

The author declares no conflict of interest.

AUTHOR CONTRIBUTIONS 
Meng-Chieh Chao conducted the research, analyzed the data, wrote the paper and had approved the final version.

\section{REFERENCE}

[1] C. D. Ekstrom, S. R. Ingman, and T. Benjamin, "Gerontology environmental links in aging education toward an intergenerational view of sustainability," Educational Gerontology, vol. 25, pp. 613-621, 1999.

[2] M. S. Kaplan, "School-based intergenerational programs," 2001.

[3] A. Hatton-Yeo and A. Ohsako, "Intergenerational programmes: Public policy and research implications an international perspective," 2000.

[4] K. P. Mendis, "The effects of participation in an intergenerational program on the psychological well-being of the elderly," Doctoral dissertation, Fordham University, 1993.

[5] M. P. S. Wenzel and S. Sorensen, "Changes in attitudes among children and elderly adults in intergenerational group work," Educational Gerontology, vol. 26, no. 6, pp. 523-540, 2000.

[6] G. Y. LinOu, "The effects of an intergenerational program on life satisfaction of nursing home residents in Northern Colorado," Doctoral dissertation, University of Northern Colorado, 2000.

[7] K. W. Hall and J. J. Batey, "Children's ideas about aging before and after an intergenerational read-aloud," Educational Gerontology, vol. 34, pp. $862-870,2008$.

[8] C. N. Gilbert, and K. G. Ricketts, "Children's attitude toward adults and aging: A synthesis of research," Educational Gerontology, vol. 34, pp. 570-586, 2008
[9] D. L. Wishard, "An analysis of children's attitudes toward older adults," Ph.D. dissertation, University of Texas at Austin, 2003.

[10] R. R. Jantz, C. Seefeldt, and K. Serock, "Children's attitude toward the elderly: Educational implication," Educational Gerontology, vol. 2, no. 3, pp. 118-122, 1978

[11] R. H. Aday, C. R. Sims, W. McDuffie, and E. Evans, "Changing children's attitudes toward the elderly: The longitudinal effects of an intergenerational partners program," Journal of Research in Childhood Education, vol. 10, no. 2, pp. 143-151, 1996.

Copyright $\odot 2019$ by the authors. This is an open access article distributed under the Creative Commons Attribution License which permits unrestricted use, distribution, and reproduction in any medium, provided the original work is properly cited (CC BY 4.0).

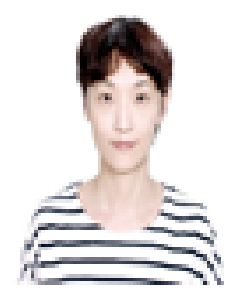

Meng-Chieh Chao is an assistant professional of Ching-Kuo Institute of Management and Health, Taiwan. She got her master degree at Chinese Culture University, majored in child welfare, and got the doctoral degree at Chung Cheng University, majored in adult education. Her academic background motivated the research activities include the areas of: a) intergenerational program; and b) parenting education. 